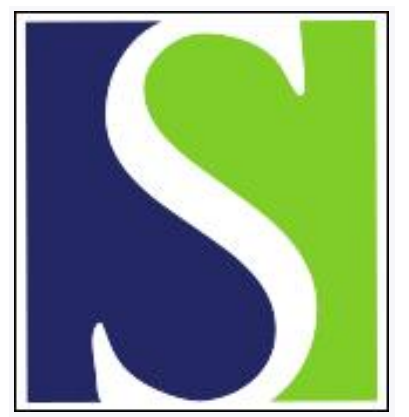

Scand J Work Environ Health 2014;40(3):244-251

https://doi.org/10.5271/sjweh.3419

Published online: 17 Feb 2014, Issue date: 01 May 2014

Workplace strength training prevents deterioration of work ability among workers with chronic pain and work disability: a randomized controlled trial

by Sundstrup E, Jakobsen MD, Brandt M, Jay K, Persson R, Aagaard P, Andersen LL

The results show that strength training prevents deterioration of work ability among slaughterhouse workers with chronic pain and work disability. Thus, strength training should be highly prioritized when designing occupational health programs aiming at maintaining work participation among employees with musculoskeletal disorders exposed to highly repetitive and forceful job tasks.

Affiliation: National Research Centre for the Working Environment, Copenhagen, Denmark. esu@nrcwe.dk

Refers to the following texts of the Journal: 2008;34(1):55-65

2009;35(1):1-5 2009;35(5):325-333 1992;18(4):257-261

2010;36(3):189-201 2011;37(6):547-550 2002;28(2):85-93

The following articles refer to this text: 2014;40(4):331-333;

2017;43(2):146-154; 2018;44(2):134-146

Key terms: biopsychosocial; carpal tunnel syndrome; chronic pain; elbow pain; ergonomic training; ergonomics; hand pain; lateral epicondylitis; musculoskeletal disorder; randomized controlled trial; resistance training; shoulder pain; strength training; WAl; work ability; work ability index; work disability; workplace strength training

This article in PubMed: www.ncbi.nlm.nih.gov/pubmed/24535014

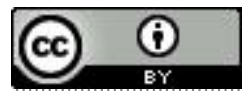




\title{
Workplace strength training prevents deterioration of work ability among workers with chronic pain and work disability: a randomized controlled trial
}

\author{
by Emil Sundstrup, MSc, ${ }^{1,2}$ Markus D Jakobsen, MSc, ${ }^{1,2}$ Mikkel Brandt, MSc, ${ }^{1}$ Kenneth Jay, MSc, ${ }^{1,2}$ \\ Roger Persson, PhD, ${ }^{3}$ Per Aagaard, PhD, ${ }^{2}$ Lars L Andersen, PhD ${ }^{1}$
}

\begin{abstract}
Sundstrup E, Jakobsen MD, Brandt MB, Jay K, Persson R, Aagaard P, Andersen LL. Workplace strength training prevents deterioration of work ability among workers with chronic pain and work disability: a randomized controlled trial. Scand J Work Environ Health. 2014;40(3):244-251. doi:10.5271/sjweh.3419
\end{abstract}

\begin{abstract}
Objective Imbalance between work demands and individual resources can lead to musculoskeletal disorders and reduced work ability. The aim of this study was to evaluate the effect of two contrasting interventions on work ability among slaughterhouse workers with chronic pain and work disability.

Methods Sixty-six slaughterhouse workers with upper-limb chronic pain and work disability were randomly allocated to 10 weeks of either strength training for the shoulder, arm, and hand muscles ( 3 times per week, 10 minutes per session) or ergonomic training (usual care control group) from September to December 2012. The outcome measure was the change from baseline to 10-week follow-up in the work ability index (WAI).

Results A priori hypothesis testing showed a group $\times$ time interaction for WAI $(\mathrm{P}<0.05)$. Compared with the ergonomic training group, WAI increased $2.3[95 \%$ confidence interval $(95 \% \mathrm{CI}) 0.9-3.7]$ in the strength training group corresponding to a moderate effect size (Cohen's $\mathrm{d} 0.52$ ). Within-group changes indicated that betweengroup differences were mainly caused by a reduction in WAI in the ergonomic group. Of the 7 items of WAI, item 2 (work ability in relation to the demands of the job) and item 7 (mental resources) increased following strength training compared with ergonomic training $(\mathrm{P}<0.05)$.

Conclusions Implementation of strength training at the workplace prevents deterioration of work ability among manual workers with chronic pain and disability exposed to forceful and repetitive job tasks. Thus, strength training performed at the workplace may in fact be regarded as a complex biopsychosocial intervention modality that reaches further than the specific physiological benefits of training per se.
\end{abstract}

Key terms biopsychosocial; carpal tunnel syndrome; elbow pain; ergonomic training; ergonomics; hand pain; lateral epicondylitis; musculoskeletal disorder; resistance training; shoulder pain; WAI; work ability index.

Musculoskeletal disorders represent the most common work-related health problem among the working population (1-3). Besides the direct effect on employee health, work-related musculoskeletal disorders are often accompanied by an escalating imbalance between work demands and individual resources consequently affecting work participation and overall working life (4).

The concept of work ability reflects the relation between the capacity of the worker and work demands, and takes into consideration work demands, health status, and physical and mental resources $(5,6)$. As a multidi- mensional instrument, the work ability index (WAI) has been associated with musculoskeletal pain, chronic disease, productivity, sickness absence, early retirement and all-cause mortality (7-11). Additionally, workers exposed to highly repetitive and forceful exertion, lack of sufficient recovery, and awkward postures $(12,13)$ have an elevated risk of both impaired work ability and musculoskeletal disorders (14-16). To prevent premature exit from the labor market, effective occupational interventions to prevent deterioration of work ability among employees with high physical work demands are warranted.

1 National Research Centre for the Working Environment, Copenhagen, Denmark.

2 Institute for Sports Science and Clinical Biomechanics, University of Southern Denmark, Odense, Denmark.

3 Department of Psychology, Lund University, Lund, Sweden. 
Slaughtering and meat processing work tasks involve high loading intensities and cyclic repetitive muscle actions of the upper limb. Combined with limited time for recovery and temporary incidents of work disability, the prevalence of musculoskeletal pain in the shoulder, arm and hand is high among slaughterhouse workers $(17,13,18)$. A prospective study among food industry employees found that multisite pain predicted poor work ability, and that the decline in work ability due to pain was greater than that observed for work-related exposures $(10,19)$. The authors concluded that pain symptoms require special attention and effective preventive measures to improve work ability and prolong working careers of employees (10). Thus, initiatives to prevent work ability deterioration may be predominantly relevant among workers with chronic pain and physical demanding job tasks (eg, slaughterhouse work).

A multitude of intervention studies on work ability have been conducted in different occupational settings, however, evidence for effective initiatives are still lacking. De Boer (20) observed no significant effect of individual counseling and education on the WAI score for employees in the construction industry with high disability risk and stated that multidisciplinary intervention programs might be necessary. A one-year randomized controlled trial among office workers found worksite physical activity programs to be effective in reducing neck and shoulder pain symptoms, however, no significant change in WAI was observed (21). Moreover, physical activity once a week at the worksite did not improve work ability among women with physically demanding laundry work (22). Furthermore, physical coordination training and cognitive behavioral training had no effect on work ability and neck/ shoulder pain among female cleaners (23). In line with these reports, van den Berg (14) concluded that the multifactorial nature of the WAI should be taken into account in health promotion programs aimed at maintaining and promoting the participation of the labor force and improvement of the performance at work. However, high drop-out rates, low adherence or incomplete questionnaire replies were present in most of the above studies, underlining the difficulties in implementing effective interventional studies at the workplace. Consequently, high quality randomized controlled intervention trials among employees with physical demanding work and chronic musculoskeletal disorders are lacking in the literature.

The present study evaluates two contrasting strategies (ie, intervention with either ergonomic or strength training) on the WAI among slaughterhouse workers with chronic pain and work disability. We hypothesized that strength training would be more effective than ergonomic training in improving work ability. The underlying assumption for this hypothesis was that previous studies have shown positive effects of strength training on musculoskeletal pain in other occupational groups (24-26).

\section{Methods}

\section{Study design}

The study was performed as a two-armed parallel group, examiner-blinded, randomized controlled trial with allocation concealment among slaughterhouse workers in Denmark from August 2012 to January 2013. The study protocol and the primary and secondary outcome (changes in shoulder, elbow, and hand pain and Disability of the Arm, Shoulder and Hand (DASH) work module, respectively) has been reported elsewhere $(18,27)$. The Danish National Ethics Committee on Biomedical Research approved the study (Ethical committee of Frederiksberg and Copenhagen; H-3-2010-062), and it was registered in ClinicalTrials.gov (NCT01671267) prior to enrolment of participants. The Consolidated Standard of Reporting Trials (CONSORT) checklist was followed to ensure transparent and standardized reporting of the trial. All participants were informed about the purpose and content of the project and gave their written informed consent to participate in the study. All experimental conditions conformed to the Declaration of Helsinki.

\section{Recruitment and flow of participants}

A screening questionnaire was distributed to 645 Danish slaughterhouse workers (aged 18-67 years) of which 595 replied and 410 were interested to participate in the research project. Initial inclusion criteria were: (i) currently working at a slaughterhouse for $\geq 30$ hours/ week, (ii) pain intensity in the shoulder, elbow/forearm, or hand/wrist of $\geq 3$ on a $0-10$ VAS scale during the last 3 months, (iii) stating at least "some" work disability scoring on a 5-point scale: "not at all", "a little", "some", "much" to "very much" when asked the question "During the last 3 months, did you have any difficulty performing your work due to pain in the shoulder, arm, or hand?", (iv) no participation in strength training during the last year, and (v) receiving no ergonomic instruction during the last year. Of the 410 interested respondents, 145 met the above inclusion criteria and were invited for a clinical examination.

A total of 135 employees were included for the baseline clinical examination. Exclusion criteria were hypertension [systolic blood pressure (BP) $>160$, diastolic BP $>100$ ], a medical history of cardiovascular diseases, carpal tunnel syndrome, recent traumatic injury of the neck, shoulder, arm or hand regions, or pregnancy. Furthermore, on the day of the clinical examination, participants completed another questionnaire with the following inclusion criteria: (i) pain intensity in the shoulder, elbow/forearm, or hand/wrist regions of $\geq 3$ on a $0-10$ VAS scale during the last week, (ii) pain lasting $>3$ months, (iii) frequency of pain of $\geq 3$ days/week during the last week. 
Based on the clinical examination and associated questionnaire, 69 workers were excluded due to contraindications: 19 showed symptoms of carpal tunnel syndrome, 4 had blood pressure $>160 / 100 \mathrm{mmHg}, 1$ had a serious cardiovascular disease, and 19 did not meet the pain inclusion criteria. Furthermore, 26 were excluded because they did not speak or understand Danish sufficiently to complete the questionnaire. The overall flow of participant enrolment is illustrated in figure 1 .

\section{Interventions}

On the basis of the clinical examination and associated questionnaire, the 66 eligible participants with chronic pain and work disability were randomly allocated to a 10 -week intervention period and assigned to receive either strength or ergonomic training (usual care, control group) at their worksite. At baseline, study participants had similar outcome expectations to the two interventions concerning the effectiveness on chronic pain (27). At the follow-up physical examination and questionnaire, all examiners were blinded to group allocation. The specific intervention activities have been described in detail elsewhere (18). In brief, subjects randomized to strength training $(\mathrm{N}=33)$ performed supervised highintensity strength training specifically for the shoulder, arm, and hand muscles during 3 sessions of 10 minutes each per week for a total of 10 weeks. Training intensity (loads) was progressively increased from 20 repetition maximum (RM) at the beginning of the training period to $8 \mathrm{RM}$ during the later phase according to the principle of periodization and progressive overload (28). All training sessions took place in designated training rooms located at the worksites and were supervised by a skilled instructor, who instructed the participants in using correct exercise techniques, and making individual exercise adjustments when needed. Additionally, participants received portable exercise equipment for home training in case of absence from work (eg, vacation).

The participants in the ergonomic group $(\mathrm{N}=33)$ received ergonomic training and education based on the practical outcomes of a worksite analysis and a hazard prevention system developed by health and safety managers and safety representatives with existing knowledge about ergonomic risk factors on the specific slaughterhouses. The intervention was implemented by health and safety managers and safety representatives at the two slaughterhouses and took place during the initial weeks of the 10-week intervention period, which corresponds to the standard worksite ergonomic prescription. The majority of the ergonomic training addressed jobspecific hands-on training where participants received appropriate guidance and training in how to correctly handle the individual work task stations.

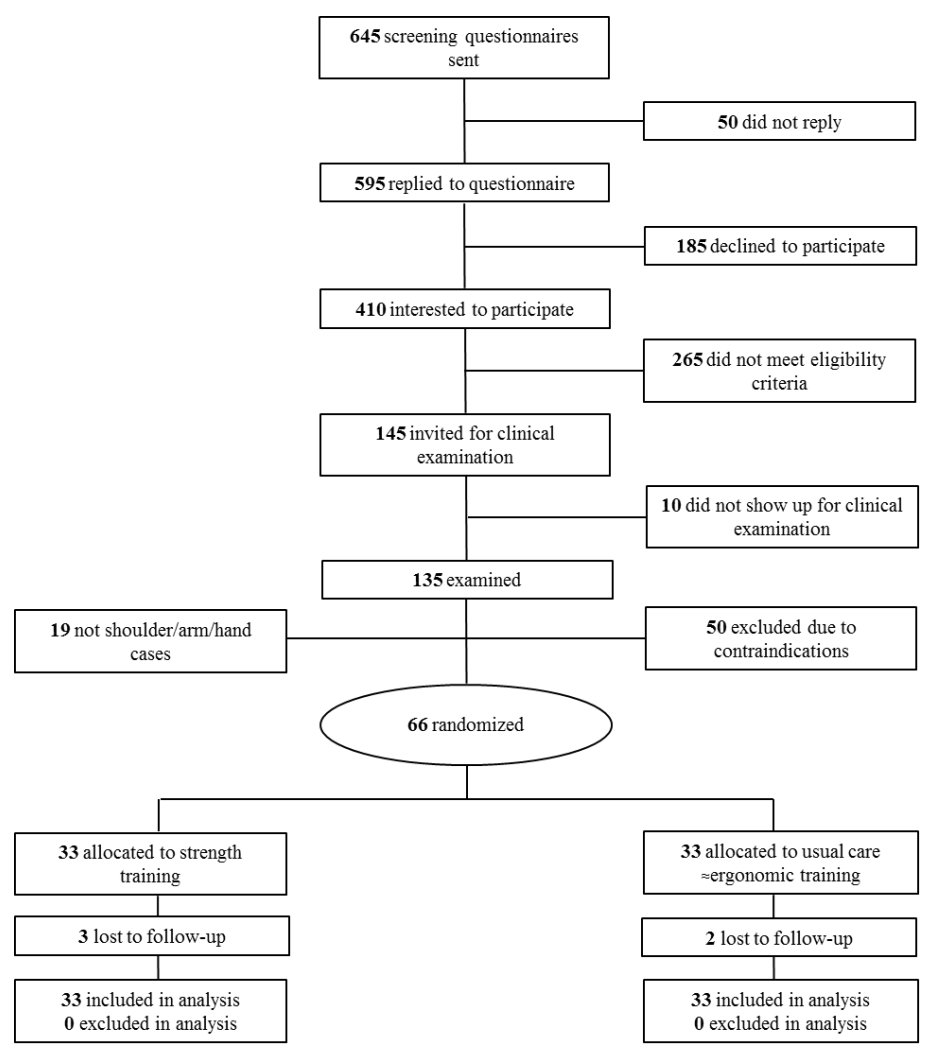

Figure. 1. Participant flow. 


\section{Outcome measures}

The outcome measure was the change from baseline to 10 -week follow-up in work ability measured by the WAI score. WAI is a composite measure of 7 items that aims to capture: (i) current work ability compared with the lifetime best, (ii) work ability in relation to the demands of the job (physical and mental demands), (iii) number of current diseases diagnosed by a physician, (iv) estimated work impairment due to diseases, (v) sick leave during the last year (12 months), (vi) own prognosis of work ability two years from now, and (vii) mental resources (worker's life in general, both at work and during leisure time ) (29). Based on the answers to the 7 items, an index score ranging from 7-49 is calculated and further classified into four categories: 7-27 (poor work ability), 28-36 (moderate work ability), 37-43 (good work ability) and 44-49 (excellent work ability) (29). Additionally we explored the contribution of each single-item score on the total WAI score by measuring the change of each of the 7 items from baseline to follow-up.

\section{Statistical analysis}

Statistical analyses were performed using SAS version 9.2 (SAS Institute, Cary, NC, USA). The outcome (ie, WAI) was analyzed according to the intention-to-treat principle using a repeated measure $2 \times 2$ analysis of variance (Proc Mixed), with time, group and time $\times$ group interaction as independent categorical variables (fixed factors). Subject nested within intervention group was entered as a random effect. Analyses were adjusted for gender, workplace, age, and WAI at baseline. In addition to the total WAI score, we also analyzed each of the seven WAI items separately using the above procedure with post hoc Bonferroni correction for multiple correlated end-points (30). All available data, ie, including baseline data of dropouts, were included in the analyses as the Proc Mixed inherently accounts for missing values. Finally we report effect sizes as Cohen's d (31) (ie, between-group differences in the WAI scores divided by the pooled standard deviation). According to Cohen (31), effect sizes of 0.20 are considered small, 0.50 moderate, and 0.80 large. An alpha level of $\leq 0.05$ was accepted as statistically significant. Outcome variables are reported as between-group least square mean differences and 95\% confidence intervals $(95 \% \mathrm{CI})$ from baseline to follow-up.

\section{Results}

\section{Study population}

Table 1 shows baseline characteristics of the study
Table 1. Baseline characteristics of the two intervention groups. [SD=standard deviation; DASH=disability of the arm, shoulder and hand.]

\begin{tabular}{|c|c|c|c|c|}
\hline & \multicolumn{2}{|c|}{$\begin{array}{l}\text { Strength } \\
\text { training }\end{array}$} & \multicolumn{2}{|c|}{$\begin{array}{l}\text { Ergonomic train- } \\
\text { ing / usual care }\end{array}$} \\
\hline & Mean & SD & Mean & SD \\
\hline Total number & 33 & & 33 & \\
\hline Number of men/women & $25 / 8$ & & $26 / 7$ & \\
\hline Age (years) & 48 & 9 & $43^{a}$ & 9 \\
\hline Height (cm) & 174 & 10 & 177 & 9 \\
\hline Weight (kg) & 83 & 20 & 86 & 17 \\
\hline BMI $\left(\mathrm{kg} / \mathrm{m}^{2}\right)$ & 28 & 6 & 28 & 5 \\
\hline Work ability index (7-49) & 39.2 & 3 & 39.4 & 3 \\
\hline $\begin{array}{l}\text { Item 1: Current work ability com- } \\
\text { pared with the lifetime best }(0-10)\end{array}$ & 7.3 & 1.0 & 7.2 & 1.0 \\
\hline $\begin{array}{l}\text { Item 2: Work ability in relation to the } \\
\text { demands of the job }(2-10)\end{array}$ & 7.5 & 0.9 & 7.5 & 0.9 \\
\hline $\begin{array}{l}\text { Item 3: Number of current diseases } \\
\text { diagnosed by a physician }(1-7)\end{array}$ & 5.6 & 0.1 & 5.6 & 0.9 \\
\hline $\begin{array}{l}\text { Item 4: Estimated work impairment } \\
\text { due to diseases }(1-6)\end{array}$ & 5.7 & 0.4 & 5.7 & 0.4 \\
\hline $\begin{array}{l}\text { Item 5: Sick leave during the past } \\
\text { year }(1-5)\end{array}$ & 4.7 & 0.6 & 4.6 & 0.6 \\
\hline $\begin{array}{l}\text { Item 6: Own prognosis of work } \\
\text { ability two years from now (1-7) }\end{array}$ & 5.5 & 0.4 & 5.7 & 0.4 \\
\hline Item 7: Mental resources (1-4) & 3.0 & 0.5 & 3.0 & 0.5 \\
\hline $\begin{array}{l}\text { Shoulder, elbow and hand pain } \\
\text { intensity previous week (scale 0-10) }\end{array}$ & 4.5 & 1.2 & 4.5 & 1.2 \\
\hline $\begin{array}{l}\text { Work disability (DASH work module; } \\
\text { scale } 0-100 \text { ) }\end{array}$ & 28.3 & 13.8 & 27.8 & 13.8 \\
\hline
\end{tabular}

a Denotes difference between groups at baseline, $\mathrm{P}<0.05$.

participants. At baseline, age was slightly higher in the strength compared with the ergonomic training group $(\mathrm{P}=0.05)$. We controlled for this difference in the mixed model ANOVA by including age as a covariate. There were no significant differences among the groups for the remainder of the variables.

Three participants in the strength training group and two in the ergonomic training group did not present for the follow-up examination, corresponding to a total of $8 \%$ loss to follow-up for the WAI questionnaire (figure 1). Adherence to strength training was $81 \%$ as participants performed on average 2.4 of the 3 intended training sessions per week.

\section{Work ability}

Figure 2 illustrates the change in WAI from baseline to 10-week follow-up. A priori hypothesis testing showed a group $\times$ time interaction for WAI scores $(\mathrm{P}<0.05)$. Compared with the ergonomic training group, WAI increased in the strength training group (table 2). No within-group change in WAI was observed for participants in the strength training group $(\mathrm{P}=0.6)$ whereas WAI decreased (ie, worsened) in the ergonomic group $(\mathrm{P}<0.01)$.

Of the 7 items of WAI, item 2 (work ability in relation to the demands of the job) and item 7 (mental resources) increased following strength compared with 


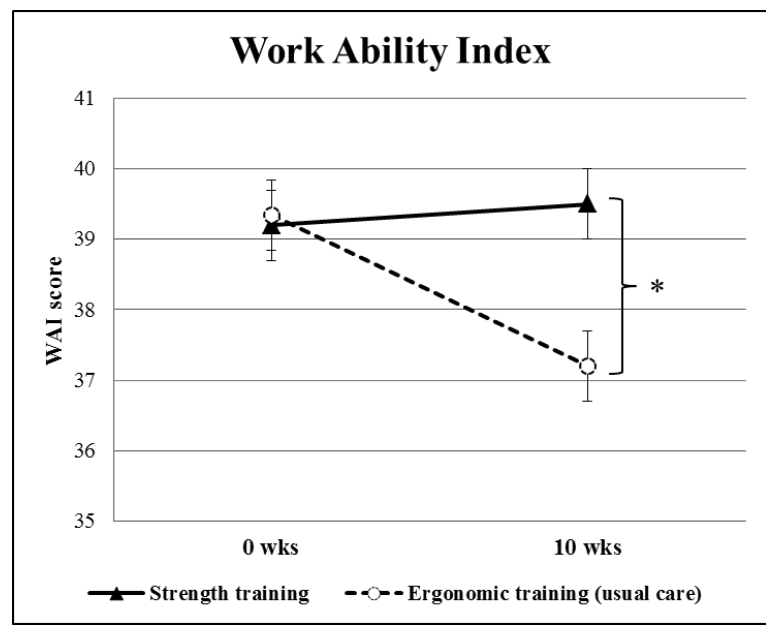

Figure. 2. Change in work ability index (WAI) from baseline (0 weeks) to follow-up (10 weeks) with strength training (full line) and ergonomic training (dashed line). Values are least square means (standard error) * Denotes greater reductions in WAI with ergonomic training compared to strength training $(\mathrm{P}<0.05)$.

ergonomic training $(\mathrm{P}<0.05$; table 2$)$. No significant differences in the remainder of the items were observed.

Effect size (Cohen's d) of the change in WAI score with strength compared with ergonomic training was 0.52 and categorized as moderate $(\geq 0.50)$.

\section{Discussion}

This randomized controlled trial showed that specific strength training at the workplace prevents deterioration of work ability among slaughterhouse workers with chronic pain and work disability.

To identify workers and work units at high risk of physical impairments, we classified the WAI score according to extant conventions into "poor" (7-27), "moderate" (28-36), "good (37-43) and "excellent" (44-49) work ability (29). The fact that the baseline average WAI score for our participants was categorized as "good", might at a first glance seem as a paradox since the inclusion criteria included both chronic pain and work disability. However, since the participants were active in the labor market and worked fulltime, our observations of relatively high scores of perceived work ability appears reasonable. Nevertheless, compared with age-matched controls without pain from the same slaughterhouses, a lower WAI score was observed among the workers with pain (unpublished data). This may be attributed to an imbalance between individual capacity and work demands, and according to the WAI score categorization, actions should be taken to maintain these employees' work ability (29).

The difference in WAI score observed post intervention between strength and ergonomic training was 2.3, and the effect size (Cohen's d 0.52) could thus be categorized as moderate. Therefore, our hypothesis was confirmed, but the difference was largely driven by a worsening in WAI score in the ergonomic group. Hence, the regime of strength training intervention appeared to prevent further deterioration in work ability effectively compared with ergonomic training. Ergonomic training (exposure reduction) generally is considered the golden standard for preventing musculoskeletal disorders at workplaces, and it is thus unlikely that ergonomic training per se caused the within-group reduction of WAI. In the present study, experienced health and safety managers and safety representatives associated with the slaughterhouses implemented the ergonomic training intervention. A key element to the interpretation of the results in the ergonomic training group could be seasonal variation in pain symptoms. Takala and coworkers (32) found a decrease in neck and shoulder pain from autumn and winter towards spring among female office

Table 2. Changes in work ability index (WAI) and single-item scores from baseline to 10-week follow-up. Pre-to-post intervention changes in each group are shown in left columns, and contrasts between the groups are shown in the right hand-side column. Single item P-values are post hoc Bonferroni corrected for multiple correlated end-points. [95\% Cl=95\% confidence interval]

\begin{tabular}{|c|c|c|c|c|c|c|c|}
\hline & \multicolumn{2}{|c|}{$\begin{array}{l}\text { Strength training } \\
\text { (difference from } \\
0-10 \text { weeks) }\end{array}$} & \multicolumn{2}{|c|}{$\begin{array}{c}\text { Ergonomic training / } \\
\text { usual care } \\
\text { (difference from } \\
0-10 \text { weeks) }\end{array}$} & \multicolumn{2}{|c|}{$\begin{array}{l}\text { Strength versus } \\
\text { ergonomic } \\
\text { (between group } \\
\text { difference) }\end{array}$} & \multirow[t]{2}{*}{ P-value } \\
\hline & Mean & $95 \% \mathrm{Cl}$ & Mean & $95 \% \mathrm{Cl}$ & Mean & $95 \% \mathrm{Cl}$ & \\
\hline WAI score & 0.3 & $-1.1-1.7$ & -2.2 & $-3.5--0.8$ & 2.3 & $0.9-3.7$ & $0.012^{\mathrm{a}}$ \\
\hline Item 1: Current work ability compared with the lifetime best $(0-10)$ & 0.0 & $-0.5-0.5$ & -0.5 & $-0.9-0.0$ & 0.5 & $0.0-1.0$ & 0.18 \\
\hline Item 2: Work ability in relation to the demands of the job (2-10) & 0.4 & $0.0-0.8$ & -0.3 & $-0.8-0.1$ & 0.7 & $0.3-1.2$ & $0.003^{\mathrm{a}}$ \\
\hline Item 3: Number of current diseases diagnosed by a physician (1-7) & -0.2 & $-0.6-0.3$ & -0.3 & $-0.7-0.1$ & 0.1 & $-0.3-0.6$ & 1.00 \\
\hline Item 4: Estimated work impairment due to diseases (1-6) & 0.1 & $-0.1-0.3$ & 0.0 & $-0.2-0.2$ & 0.0 & $-0.2-0.2$ & 1.00 \\
\hline Item 5: Sick leave during the past year (1-5) & -0.2 & $-0.6-0.0$ & -0.5 & $-0.8--0.2$ & 0.2 & $-0.1-0.5$ & 0.47 \\
\hline Item 6: Own prognosis of work ability two years from now (1-7) & 0.2 & $-0.5-0.8$ & -0.3 & $-0.9-0.3$ & 0.3 & $-0.4-1.0$ & 1.00 \\
\hline Item 7: Mental resources (1-4) & 0.1 & $-0.1-0.4$ & -0.3 & $-0.5-0.0$ & 0.3 & $0.1-0.6$ & $0.021^{a}$ \\
\hline
\end{tabular}

a Denotes significant difference $\mathrm{P}<0.05$. 
workers and linked it to seasonal affective disorders (SAD). SAD is characterized by symptoms of depression such as low mood, concentration problems, loss of energy and fatigue with symptoms developing during fall and early winter (33). Thus, seasonal variation could have influenced the results of the WAI as baseline testing and questionnaire was administered in August and September and follow-up in December. In line with this notion, Takala et al concluded, that a seasonal variation in symptoms should be considered when preventive programs for neck and shoulder disorders are planned and evaluated (32). This also highlights the importance of a usual care control group when evaluating the effect of new interventions.

Analyzing the items of WAI separately revealed a between-group difference in items 2 and 7 concerning work ability in relation to the demands of the job and mental resources, respectively. The strength training program led to significant muscle strength gains in the upper limb, which theoretically results in a lower relative exposure during high-force, high repetition slaughterhouse work $(27,34)$. Consequently, the imbalance between individual physical capacity and physical work demands potentially would be reduced, possibly explaining the observed difference in demands of the job (item 2 ) between the two groups. Although we did not measure relative exposure during work, a recent study using electromyography has shown lower relative exposure of the neck muscles among office workers during the working day following 10 weeks of strength training (35).

To better comprehend the between-group change in mental resources (item 7) we should allude to the biopsychosocial model of chronic pain, which is a widely accepted model focusing on the complex interaction between biological, psychological, and social factors in the neurological perception of pain (36). Patients with chronic pain are at increased risk of emotional disorders (eg, anxiety and depression), maladaptive cognitions (eg, catastrophizing and poor coping skills), functional deficits and physical decondition (due to decreased physical activity and fear avoidance) (36). Because all these variables are interdependent, interventions effective in reducing chronic pain would theoretically in parallel treat other dimensions of chronic pain perception as well. The questions in item 7 on mental resources relate to emotion, cognition, and behavior of the workers life in general, both at work and during leisure time. Thus, the present results may reflect (i) the influence of strength training as a potent tool for chronic pain management, (ii) the participants in the ergonomic group being more affected by their chronic pain, or (iii) a combination of both.

Numerous intervention studies focusing on WAI have been conducted, however, no or only minor changes have been reported $(14,21-23)$. Blangsted
(21) proved specific strength training and general physical activity to be effective in reducing neck and shoulder pain symptoms among office workers compared with inactive controls, however no change in WAI was observed. However, that study enrolled office workers in general and not specifically those with pain and disability. Additionally, no change in sick leaves and WAI score were observed following eight months of muscle strengthening, cardiovascular exercise, and stretching, suggesting that work ability may not be influenced by single-component exercise interventions (22). In line with this notion, a review on individual factors of the WAI, stated that the multifactorial nature of the WAI should be taken into account when designing programs aimed at maintaining and promoting the participation of the labor force and improvement of performance at work (14). In contrast, the present study showed that strength training compared with ergonomic intervention effectively prevents reduction in WAI among slaughterhouse workers with chronic pain. Although some may consider strength training a single-component exercise intervention, the mutual involvement of workers, leaders, and organization at the slaughterhouses in the planning phase of the study and the group-based exercise regimen during the 10-week intervention may have induced both social and psychological benefits. In the present study, group-based strength exercise sessions were prioritized and instructors trained to supervise pain management, focus on positive feedback, and promote social engagement among participants. A previous study from our research group showed that 8-weeks of group-based kettle-bell training at the workplace led to improved wellness and social relationships among colleagues (37). Together with the potent effect on chronic pain (27), which is composed of complex biopsychosocial interactions, strength training is a relevant workplace tool to influence the multidimensional WAI positively. Thus, strength training performed at the workplace in the company of colleagues may in fact be regarded as a complex biopsychosocial intervention modality that reaches further than the specific physiological benefits of training per se. Future studies could evaluate this potential effect (eg, by comparing workplace versus home-based physical exercise) on social capital and workers well-being at the workplace.

The present study has both strengths and limitations. The randomized controlled design with concealed allocation and blinded clinical examiners protects against systematic bias. Further, the low drop-out of participants at follow-up, the high adherence to the intervention regimes, and inclusion of drop-outs in the statistical analysis allowed us to test the actual effect of the interventions. A general weakness of behavioral interventions is that blinding of participants and those administrating the intervention is not possible. Accordingly, perceived 
work ability measured by the WAI may be influenced by outcome expectations. However, to minimize this type of bias we included two active interventions groups rather than comparing treatment with an inactive waiting list group. A strength of our study was that participant outcome expectations at baseline were similar in the strength and ergonomic training intervention groups, suggesting that placebo effects were unlikely to differentially affect the two groups. Finally, the exclusion and inclusion criteria used in the present study confine the generalizability of our results to workers with chronic pain in the arm, shoulder, and hand regions and those exposed to highly repetitive and forceful work.

\section{Concluding remarks}

The present study demonstrated a significant effect of strength compared with ergonomic training on work ability (WAI) among slaughterhouse workers with chronic pain and work disability. This difference was largely driven by a reduction (ie, worsening) of WAI in the ergonomic group. Of the 7 WAI items, item 2 (work ability in relation to the demands of the job) and item 7 (mental resources) were improved following strength compared with ergonomic training. Thus, strength training appears effective in preventing deterioration in work ability among slaughterhouse workers with chronic pain and work disability and could therefore be regarded as a complex biopsychosocial intervention modality that reaches further than the specific physiological benefits of training per se.

\section{Acknowledgment}

This study was supported by a grant from the Danish Parliament (Satspuljen 2012; Nye Veje, grant number $\S$ 17.21.02.60) and a grant from the Danish Working Environment Research Fund (Grant no. 48- 2010-03).

The authors declare no conflicts of interest.

\section{References}

1. European Agency for Safety and Health at Work. European risk observatory report, OSH in figures: Work-related musculoskeletal disorders in the EU - Facts and Figures. Luxembourg: Publications Office of the European Union; 2010.

2. US Department of Labor. Nonfatal Occupational Injuries and Illnesses Requiring Days Away From Work, 2012 [Internet]. Bureau of Labor Statistics, Washington, D.C; 2012. Available from: http://www.bls.gov/news.release/osh2.nr0.htm
3. Punnett L, Wegman DH. Work-related musculoskeletal disorders: the epidemiologic evidence and the debate. JElectromyogrKinesiol. 2004 Feb;14(1):13-23. http://dx.doi. org/10.1016/j.jelekin.2003.09.015.

4. Kamaleri Y, Natvig B, Ihlebaek CM, Benth JS, Bruusgaard D. Number of pain sites is associated with demographic, lifestyle, and health-related factors in the general population. Eur J Pain Lond Engl. 2008 Aug;12(6):742-8. http://dx.doi. org/10.1016/j.ejpain.2007.11.005.

5. Ilmarinen J, Tuomi K. Past, Present and Future of Work Ability. People Work -Res Rep J Hels Finl Finn Inst Occup Health. 2004;65: 581-9.

6. Ilmarinen J. Work ability--a comprehensive concept for occupational health research and prevention. Scand J Work Environ Health. 2009 Jan;35(1):1-5. http://dx.doi. org/10.5271/sjweh.1304.

7. Tuomi K, Ilmarinen J, Eskelinen L, Järvinen E, Toikkanen J, Klockars M. Prevalence and incidence rates of diseases and work ability in different work categories of municipal occupations. Scand J Work Environ Health. 1991;17 Suppl $1: 67-74$.

8. Alavinia SM, de Boer AGEM, van Duivenbooden JC, FringsDresen MHW, Burdorf A. Determinants of work ability and its predictive value for disability. Occup Med Oxf Engl. 2009 Jan;59(1):32-7. http://dx.doi.org/10.1093/occmed/kqn148.

9. Seitsamo J, Martikainen R. Work ability and all cause mortality; A 25-year longitudinal study among Finnish municipal workers. Promotion of workability towards productive ageing. London: Taylor and Francis Group Kumashiro M; 2009. p101-104.

10. Neupane S, Miranda H, Virtanen P, Siukola A, Nygård C-H. Multi-site pain and work ability among an industrial population. Occup Med Oxf Engl. 2011 Dec;61(8):563-9. http://dx.doi.org/10.1093/occmed/kqr130.

11. Vänni K, Virtanen P, Luukkaala T, Nygård C-H. Relationship between perceived work ability and productivity loss. Int J Occup Saf Ergon JOSE. 2012;18(3):299-309.

12. Van Rijn RM, Huisstede BM, Koes BW, Burdorf A. Associations between work-related factors and specific disorders of the shoulder--a systematic review of the literature. Scand J Work Environ Health. 2010 May;36(3):189-201. http://dx.doi.org/10.5271/sjweh.2895.

13. Bernard B.P. Musculoskeletal disorders and workplace factors: A critical review of epidemiologic evidence for work-related musculoskeletal disorders of the neck, upper extremity, and low back. Washington, DC: US Department of Health and Human Servises. Public Health Service, Center for Disease Control and Prevention, National Institute for Occupational Safety and Health; 1997.

14. Van den Berg TIJ, Elders LAM, de Zwart BCH, Burdorf A. The effects of work-related and individual factors on the Work Ability Index: a systematic review. Occup Environ Med. 2009 Apr;66(4):211-20. http://dx.doi.org/10.1136/ oem.2008.039883.

15. Alavinia SM, van den Berg TIJ, van Duivenbooden C, Elders 
LAM, Burdorf A. Impact of work-related factors, lifestyle, and work ability on sickness absence among Dutch construction workers. Scand J Work Environ Health. 2009 Oct;35(5):32533. http://dx.doi.org/10.5271/sjweh.1340.

16. Andersen JH, Haahr JP, Frost P. Risk factors for more severe regional musculoskeletal symptoms: a two-year prospective study of a general working population. Arthritis Rheum. 2007 Apr;56(4):1355-64. http://dx.doi.org/10.1002/art.22513.

17. Sommerich CM, McGlothlin JD, Marras WS. Occupational risk factors associated with soft tissue disorders of the shoulder: a review of recent investigations in the literature. Ergonomics. 1993 Jun;36(6):697-717. http://dx.doi. org/10.1080/00140139308967931.

18. Sundstrup E, Jakobsen MD, Andersen CH, Jay K, Persson $\mathrm{R}$, Aagaard P, et al. Participatory ergonomic intervention versus strength training on chronic pain and work disability in slaughterhouse workers: study protocol for a single-blind, randomized controlled trial. BMC Musculoskelet Disord. 2013;14:67. http://dx.doi.org/10.1186/1471-2474-14-67.

19. Neupane S, Virtanen P, Leino-Arjas P, Miranda H, Siukola A, Nygård C-H. Multi-site pain and working conditions as predictors of work ability in a 4-year follow-up among food industry employees. Eur J Pain Lond Engl. 2013 Mar;17(3):444-51. http://dx.doi.org/10.1002/j.15322149.2012.00198.x.

20. De Boer AGEM, Burdorf A, van Duivenbooden C, FringsDresen MHW. The effect of individual counselling and education on work ability and disability pension: a prospective intervention study in the construction industry. Occup Environ Med. 2007 Dec;64(12):792-7. http://dx.doi.org/10.1136/ oem.2006.029678.

21. Blangsted AK, Søgaard K, Hansen EA, Hannerz H, Sjøgaard G. One-year randomized controlled trial with different physical-activity programs to reduce musculoskeletal symptoms in the neck and shoulders among office workers. Scand J Work Environ Health. 2008 Feb;34(1):55-65. http:// dx.doi.org/10.5271/sjweh.1192.

22. Nurminen E, Malmivaara A, Ilmarinen J, Ylöstalo P, Mutanen $\mathrm{P}$, Ahonen $\mathrm{G}$, et al. Effectiveness of a worksite exercise program with respect to perceived work ability and sick leaves among women with physical work. Scand J Work Environ Health. 2002 Apr;28(2):85-93. http://dx.doi.org/10.5271/ sjweh.652.

23. Jørgensen MB, Faber A, Hansen JV, Holtermann A, Søgaard K. Effects on musculoskeletal pain, work ability and sickness absence in a 1-year randomised controlled trial among cleaners. BMC Public Health. 2011;11:840. http://dx.doi. org/10.1186/1471-2458-11-840.

24. Andersen LL, Jakobsen MD, Pedersen MT, Mortensen OS, Sjøgaard G, Zebis MK. Effect of specific resistance training on forearm pain and work disability in industrial technicians: cluster randomised controlled trial. BMJ Open. 2012;2(1):e000412. http://dx.doi.org/10.1136/ bmjopen-2011-000412.

25. Andersen LL, Andersen JL, Suetta C, Kjaer M, Søgaard
K, Sjøgaard G. Effect of contrasting physical exercise interventions on rapid force capacity of chronically painful muscles. J Appl Physiol. 2009 Nov;107(5):1413-9.

26. Andersen LL, Mortensen OS, Zebis MK, Jensen RH, Poulsen OM. Effect of brief daily exercise on headache among adults-secondary analysis of a randomized controlled trial. Scand J Work Environ Health. 2011 Nov;37(6):547-50. http://dx.doi. org/10.5271/sjweh.3170.

27. Sundstrup E, Jakobsen MD, Andersen CH, Jay K, Persson R, Aagaard P, et al. Effect of two contrasting interventions on upper limb chronic pain and disability: Randomized controlled trial. Pain Physician. 2014 Mar-Apr;17(2):145-54.

28. American College of Sports Medicine. American College of Sports Medicine position stand. Progression models in resistance training for healthy adults. Med Sci Sports Exerc. 2009 Mar;41(3):687-708. http://dx.doi.org/10.1249/ MSS.0b013e3181915670.

29. Tuomi K, Ilmarinen J, Jahkola A, Katajarinne L, Tulkki A. Work Ability Index. $2^{\text {nd }}$ revised ed. Helsinki: Finnish Institute of Occupational Health, 1998.

30. Shi Q, Pavey ES, Carter RE. Bonferroni-based correction factor for multiple, correlated endpoints. Pharm Stat. 2012 Aug;11(4):300-9. http://dx.doi.org/10.1002/pst.1514.

31. Cohen, J. Statistical Poer Analysis for the Behavioral Sciences. Lawrence Erlbaum Associates; 1988.

32. Takala EP, Viikari-Juntura E, Moneta GB, Saarenmaa K, Kaivanto K. Seasonal variation in neck and shoulder symptoms. Scand J Work Environ Health. 1992 Aug;18(4):257-61. http:// dx.doi.org/10.5271/sjweh.1580.

33. Magnusson A, Boivin D. Seasonal affective disorder: an overview. Chronobiol Int. 2003 Mar;20(2):189-207. http:// dx.doi.org/10.1081/CBI-120019310.

34. Andersen LL, Andersen CH, Zebis MK, Nielsen PK, Søgaard K, Sjøgaard G. Effect of physical training on function of chronically painful muscles: a randomized controlled trial. J Appl Physiol. 2008 Dec;105(6):1796-801.

35. Lidegaard, M, Jensen BR, Andersen CH, Zebis MK, Colado JC, Wang Y, et al. Effect of brief daily resistance training on occupational neck/shoulder muscle activity in office workers with chronic pain: Randomized controlled trial. BioMed Res Int. Volume 2013 (2013), Article ID 262386. http://dx.doi. org/10.1155/2013/262386

36. Gatchel RJ, Peng YB, Peters ML, Fuchs PN, Turk DC. The bio psychosocial approach to chronic pain: scientific advances and future directions. Psychol Bull. 2007 Jul;133(4):581-624. http://dx.doi.org/10.1037/0033-2909.133.4.581.

37. Jay K, Jakobsen MD, Sundstrup E, Skotte JH, Jørgensen MB, Andersen $\mathrm{CH}$, et al. Effects of kettle bell training on postural coordination and jump performance: A randomized controlled trial. J Strength Cond Res Natl Strength Cond Assoc [Internet]. 2012 Jul 26 [cited 2012 Aug 28]; Available from: http://www. ncbi.nlm.nih.gov/pubmed/22843044

Received for publication: 19 December 2013 